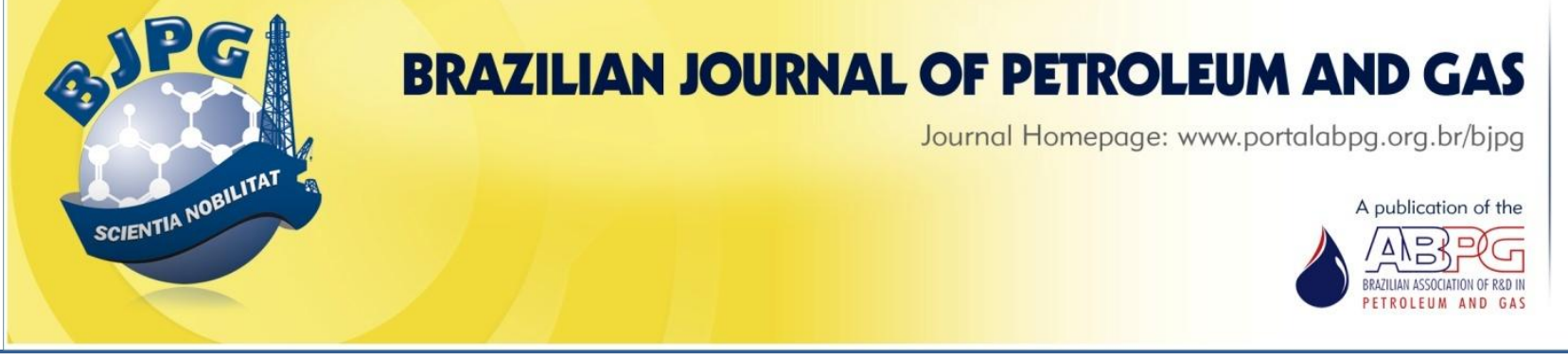

\title{
EFFECTS OF THE ADDITION OF [2HEA][HX] ON BIODIESEL SYNTHESIS USING METHANOL AND METHANOL/ETHANOL MIXTURE
}

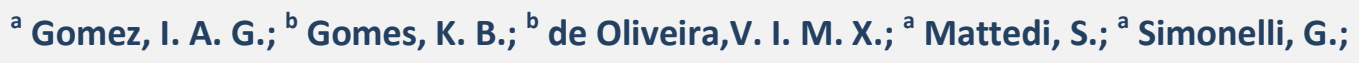

${ }^{a}$ Santos, L. C. L., ${ }^{a}$ bobato, A. K. C. L. ${ }^{1}$

${ }^{\text {a }}$ Federal University of Bahia, Graduate Program of Chemical Engineering, Salvador - BA - Brazil

${ }^{b}$ Salvador University, School of Architecture, Engineering, and Information Technology, Salvador - BA - Brazil

Received: 19.03.2019 / Revised: 04.06.2019 / Accepted: 19.06.2019 / Published on line: 08.10.2019

\begin{abstract}
Currently, the use of ionic liquids (ILS), such as catalysts and co-solvents, in the production of biodiesel commonly demands extreme operating conditions (especially temperature and / or time). Besides the environmental benefits, these compounds have versatile physical and chemical properties. Some of these compounds also possess amphiphilic features that allow them to act as surfactants and, in this case, when employed as additives in transesterification reactions, they can overcome mass transfer limitations and, consequently, the reaction rate. This work aims at studying the effects of protic ionic liquid (PIL) 2hydroxyethylammonium hexanoate $[2 \mathrm{HEA}][\mathrm{Hx}]$ in the alkaline transesterification of soybean oil using methanol and a methanol/ethanol mixture. The reaction conditions were alcohol/oil molar ratio of 6:1, $1.5 \%$ (\%wt/wt) $\mathrm{KOH}$ as the catalyst, $2 \%$ (\%wt/wt) PIL as the additive, $60{ }^{\circ} \mathrm{C}$, and $30 \mathrm{~min}$ reaction time. The highest mass yield was $92.72 \%$ for both pure methanol and methanol/ethanol mixture (molar ratios 5:1), since the mean was not statistically different for those two ratios.
\end{abstract}

\section{KEYWORDS}

biodiesel; transesterification; methanol/ethanol mixture; protic ionic liquid; co-solvent

\footnotetext{
${ }^{1}$ To whom all correspondence should be addressed.

Address: School of Architecture, Engineering, and Information Technology, Salvador University, R. Dr. José Peroba, 251-Stiep, ZIP Code 41770-235, Salvador/BA, Brazil, and Graduate Program of Chemical Engineering, Federal University of Bahia, R. Prof. Aristides Novis, 2, 2o andar, Federação, ZIP Code 40210-630, Salvador/BA, Brazil.

e-mail: ana.lobato@unifacs.br

doi:10.5419/bjpg2019-0015
} 


\section{INTRODUCTION}

Biofuels are alternative energy sources with the potential to meet energy needs in the field of fuels (Guimarães et al., 2018, Ullah et al., 2018). Biodiesel, which belongs the family of biofuels, is obtained from vegetable oils, animal fats, algae lipids, waste oils, and hydrogenated fats. For this reason, it is considered a clean, renewable, biodegradable, and nontoxic alternative to fossil fuels (Moro et al., 2017; Verma \& Sharma, 2016). It can be used either to replace diesel or as an additive, reducing the emission of greenhouse gases and sulfur oxides, thus, improving gas combustion emission profile (Khudhair et al., 2018; Ullah et al., 2018).

Fatty acids alkyl esters (biodiesel), as a final product, and glycerol, as co-product, are obtained mostly through the transesterification (reversible chemical reaction) of triglycerides, which react with an excessive amount of alcohol in the presence of a catalyst (Feng et al., 2017; Guimarães et al., 2018; Keera et al., 2011; Verma \& Sharma, 2016).

Both methanol and ethanol have been used successfully in the production of biodiesel ( $\mathrm{Ma}$ et al., 2015). Methanol is the often the first choice due to its physical and chemical properties. However, is not considered a completely ecofriendly alternative, whereas ethanol is. Additionally, it has greater solubility in oils than methanol. Nevertheless, ethanol can produce steric and emulsification effects after transesterification, which difficult the purification of biodiesel and compromises the yield of the process (Khudhair et al., 2018; Li et al., 2013; Ma et al., 2015; Verma \& Sharma, 2016).

The type of alcohol and the molar ratios influence biodiesel yield and its properties. Studies using the methanol/ethanol mixtures have been conducted in an attempt to benefit from the synergistic effect and the specific properties of homogeneous and heterogeneous catalysts (Khudhair et al., 2018; Lam \& Li, 2011; Ma et al., 2015; Ma et al., 2016).

The catalysts used in the transesterification reaction can be homogeneous, heterogeneous, or enzymatic (Verma \& Sharma, 2016). Alkaline catalysts are used more commonly (Simonelli et al., 2018) due to their intense activity in mild operating conditions (Issariyakul \& Dalai, 2014). In this regard, ionic liquids have also been used as catalysts in the synthesis of biodiesel.

Ionic liquids (ILS) are organic salts in the liquid state below $100{ }^{\circ} \mathrm{C}$, produced by cation (organic compound) and anion (organic and inorganic compound) combinations, with either hydrophobic or hydrophilic nature. These solvents have been used in several applications, such as in the synthesis of biodiesel, acting as catalysts, cosolvents; and as extraction agents in the purification process (Álvarez et al., 2010; Fauzi \& Amin, 2012; Troter et al., 2016).

ILs present important physical and chemical properties, which include biodegradability, negligible vapor pressure, high miscibility in organic and inorganic solvents, high ionic conductivity, remarkable catalyst activity, high thermal and chemical stability, and the possibility of setting up their properties, being projectable (Camargo et al., 2016., Feng et al., 2017; Muhammad et al., 2015). They can be protic (PIL) and aprotic (AIL) (Camargo et al., 2016).

PILs have low production costs and are easily synthesized by protons transfer from an acid to a Brønsted base, in which the cation has an interchangeable proton that allows the formation of hydrogen bonds with the anion (Muhammad et al.; 2015; Shmukler et al., 2018).

Studies using ILs in biodiesel production, in their vast majority, have reported demanding operating conditions, environmental benefits, and process improvements. Their use as catalysts (homogeneous, heterogeneous, or self-supported) shows good potential to improve the synthesis process but, demands, among other variables, higher process temperatures compared to the use of traditional homogeneous or heterogeneous catalysts. In these studies, the aprotic ionic liquids are the most assessed (Fauzi \& Amin, 2012; Feng et al., 2017; Ullah et al., 2018; Zanin et al., 2013). As co-solvents, ILs have been used mostly in enzymatic catalysis (Fan et al., 2018; Troter et al., 2016). Basically, two types of ILs have been studied. The first type, ILs with a more hydrophobic nature, which has shown good performance, increasing the catalytic activity and reaction rate. In addition, they improve oil transesterification and favor the biodiesel separation. The second type, ILS with hydrophilic features that are capable of promoting enzyme dissolution or denaturing, 
showing lowest yields (Muhammad et al., 2015; Troter et al., 2016).

Some ILs have surfactant features due to their amphiphilic properties. Even in low concentrations, they can reduce interfacial tension in aqueous solutions and form micelles. In this regard, the interfacial behavior of some protic ILs have been explored. For instance, Santos et al. (2014) proved that ILs based on a 2-hydroxyethylammonium cation, bis (2-hydroxyethylammonium), and stearate anion in aqueous solutions formed micelles. In a previous work from our group, Trindade et al. (2019) studied the action of a PIL, also designed from an amine and carboxylic acid (diethylenetriammonium hexanoate), in the reaction medium via homogeneous catalysis. The PIL showed good performance and promising results.

The interfacial behavior of some substances has already been employed to overcome common mass transfer restrictions in transesterification. In some studies, organic surfactants and co-solvents, (e.g., acetone, esters, tetrahydrofuran, and hexane) have been used as additive to increase mixture efficiency, contact and mutual solubility between the immiscible phases and, consequently, improve the reaction rate in the transesterification and yield in biodiesel These organic co-solvents generally are used in high amounts $14.5 \%-25 \%$ (\%wt/wt) with reference to the oil mass, additionally, they are toxic, volatile, and generate wastes that are difficult to separate and discard (Alhassan et al., 2014; Encinar et al., 2016; Fadhil et al., 2015; Simonelli et al., 2018; Wu et al., 2016).

This study employs the PIL 2-hydroxyethyl ammonium hexanoate ([2HEA][Hx]), with potential to develop interfacial activity. The anion group is hexanoate $[\mathrm{Hx}]$, the same as that used by Trindade et al. (2019), [DETA][Hx]. This anion was chosen because it has the polar carboxyl and apolar carbon chain, similar to the stearic one proposed by Santos et al. (2014), but with a lower carbonic chain and lower viscosity. These domains in the anion chain suggest that they could exhibit surfactant behavior necessary to promote the formation of micelles. The cation 2hydroxyethylammonium [2HEA] was chosen due to the presence of hydroxyl group on the chemical structure and the structural similarity with the solvent medium. Considering the excess of alcohol used in the transesterification, this group could facilitate the solubility in the reaction medium, contributing to the increase of the effect surfactant of $[2 \mathrm{HEA}][\mathrm{Hx}]$. Additionally, the base used (ethanolamine) is inexpensive, and equal amounts of both the acid and the base are required to synthesize it.

Departing from the application of Lls as both catalysts and co-solvents, this work seeks to explore whether the surfactant potential of [2HEA][Hx] is sufficient to allow an increase in the miscibility, and if this is would be possible using a low amount of PIL in such a way that it could be applied as an additive in biodiesel production.

Previous research has not explored the use of this PIL in the production of biodiesel, employing the reactional medium of transesterification alkaline. Additionally, there have been few studies that touch upon the application of the LIs as an additive in homogenous catalysis.

This work studies the alkaline transesterification of soybean oil using methanol and a methanol/ethanol mixture combined with the effect the PIL [2HEA][Hx]. To this end, we evaluated the effect of PIL [2HEA][Hx] at different proportions of alcohols and determined how the additive influences biodiesel yield. Temperature, time, amount of $\mathrm{KOH}$, and the alcohol-oil molar ratio were kept fixed.

\section{MATERIALS AND METHODS}

This study employed soybean oil (Soya ${ }^{\circ}$ brand), methanol (Synth, 99.8\% pure), ethanol (Synth, 99.5\% pure), potassium hydroxide- $\mathrm{KOH}$ (SigmaAldrich Vetec $^{\mathrm{TM}}$, $85 \%$ pure), ethanolamine $\mathrm{NH}_{2} \mathrm{CH}_{2} \mathrm{CH}_{2} \mathrm{OH}$ (CAS Registry N. 141-43-5), and hexanoic acid $\mathrm{CH}_{3}\left(\mathrm{CH}_{2}\right)_{4} \mathrm{COOH}$ (CAS Registry No. 142-62-1).

\subsection{Characterization of the soybean oil}

The physical characterization of the raw material comprised four tests. The acidity index (ABNT NBR 11115, 2014) was determined by titrimetric analysis. The water content was determined using the gravimetric method in accordance with the procedure defined in the ANVISA 2008 standard (ANVISA, 2008). Density at 
$20{ }^{\circ} \mathrm{C}$ (ASTM D 4052-16, 2016) was measured using an Anton Paar DSA 5000 density meter.

Finally, the kinematic viscosity $\left(v_{\text {sample }}\right)$, at $40{ }^{\circ} \mathrm{C}$ (ASTM D 445-17a, 2017) was calculated based on the absolute viscosity of soybean oil at $40{ }^{\circ} \mathrm{C}$ $\left(\mu_{\text {sample }}\right)$ which, in turn, was measured with an Anton Paar MCR 501 rheometer and, then, related to the density ( $\rho_{\text {sample }}$ ) of soybean oil, by Equation 1. All tests were done in triplicate.

$v_{\text {sample }}=\frac{\mu_{\text {sample }}}{\rho_{\text {sample }}}$

\subsection{Synthesis and characterization of the protic ionic liquid}

The 2-hydroxyethyl ammonium hexanoate ([2HEA] [Hx]) was synthesized via a stoichiometric neutralization reaction between ethanolamine and hexanoic acid. The acid was slowly added to the base, dropwise, under slow mechanical stirring, at $40{ }^{\circ} \mathrm{C}$. Since the reaction is exothermic, a slight increase in temperature improves the miscibility between the reagents (Camargo et al., 2016; Pinto et al., 2015). The process results in an ammonium salt, being water its main impurity. Some studies have reported the presence water in protic ionic liquids as a result of the neutralization by ammonia, due to the hygroscopic features (Álvarez et al., 2010; Pinto et al., 2015). Figure 1 shows the combination reaction.

The formation of [2HEA] [Hx]) was confirmed and its chemical structure was characterized through carbon and hydrogen analysis, using FT-IR and NMR techniques. Additionally, humidity (\% $\mathrm{H}_{2} \mathrm{O}$ ) was determined using the Karl Fisher method (Álvarez et al., 2010; Fauzi \& Amin, 2012; Penttila et al., 2014)

The FT-IR spectra were obtained using a Shimadzu IR Prestige 21 spectrophotometer. The NMR spectra for hydrogen $\left({ }^{1} \mathrm{H}\right)$ and carbon $\left({ }^{13} \mathrm{C}\right)$ were recorded with a Brunker DRX 400 spectrometer at 9.39 tesla and $400 \mathrm{MHz}$, using the spectra processing software Mestre Nova 11.0. $\mathrm{CDCl}_{3}$ was used as solvent for the proton spectrum and as a reference for the carbon spectrum, where the capillary tube was coaxially inserted in the NMR tube. Deuterated 3- (trimethylsilyl) propanoic acid (TSP) was used to calibrate the signal in $\sim 0$ ppm. Humidity $\left(\% \mathrm{H}_{2} \mathrm{O}\right)$ of the IL was measured using a Mettler Toledo V20 volumetric Karl Fisher titrator. The use of ${ }^{1} \mathrm{H}$ NMR technique to determine the presence and amount of water in the sample presents some limitations (Penttila et al., 2014), since some impurity identification peaks, such as water, overlap the spectra and cannot be quantified. Therefore, more specific methods should be employed to achieve more accurate results.

\subsection{Biodiesel production}

Biodiesel was synthesized through a batch process using alkaline transesterification. During the synthesis, the following process variables were kept fixed: alcohol-oil molar ratio $(6: 1)$, catalyst $1.5 \%$ (\% wt/wt), PIL [2HEA][Hx] $2 \%$ (\% wt/wt), time (30 min), temperature $\left(60{ }^{\circ} \mathrm{C}\right.$ ), methanol (molar ratio 6:0), and a methanol/ethanol mixture (molar ratios 4:2, 5:1, 6:0) the latter two were used as transesterification agents. Tests in the presence and absence of PIL were performed in triplicate. For each test, $100 \mathrm{~g}$ soybean oil were placed in a flat bottom flask. Then, the amount of $\mathrm{KOH}$ was measured and added to the transesterification agent (departing from pure methanol) under magnetic stirring to homogenize them and, finally, the PIL [2HEA][Hx] was added (under the same conditions).The resulting mixture was, then, added to the oil in the flat bottom flask and put on a magnetic stirrer $(600 \mathrm{rpm})$ heating plate (Ika ${ }^{\circ} \mathrm{C}$ MAG HS 7) (Simonelli et al., 2018). The system was attached to a condenser associated with an ultrathermostatic bath device (Quimis ${ }^{\circ}$ Q214M2), which was set to $15^{\circ} \mathrm{C}$, thus, keeping the alcohol vapors in the system. After the reaction completion<smiles>CCCCCC(=O)[O-]</smiles>

Figure 1. Neutralization reaction of $[2 \mathrm{HEA}][\mathrm{Hx}]$. 
Table 1. Physical and chemical characterization of soybean oil.

\begin{tabular}{|c|c|c|c|c|}
\hline \multirow{2}{*}{$\begin{array}{l}\text { Properties } \\
\text { (Unit) }\end{array}$} & \multirow[b]{2}{*}{ Value } & \multicolumn{3}{|c|}{ References } \\
\hline & & $\begin{array}{c}\text { Simonelli et al. } \\
2018\end{array}$ & $\begin{array}{c}\text { Cintra et al. } \\
2017\end{array}$ & $\begin{array}{c}\text { Keera et al. } \\
2011\end{array}$ \\
\hline $\begin{array}{l}\text { Acidity index } \\
\left(\mathrm{mg} \mathrm{KOH} . \mathrm{g}^{-1}\right)\end{array}$ & $0.30 \pm 0.05$ & $0.59 \pm 0.03$ & 0.091 & 0.42 \\
\hline Water Content (\%) & $0.07 \pm 0.04$ & $0.1032 \pm 0.0008$ & 0.103 & $*$ \\
\hline $\begin{array}{c}\text { Density at } 20^{\circ} \mathrm{C} \\
\left(\mathrm{g} . \mathrm{cm}^{-3}\right)\end{array}$ & $0.916 \pm 0.004$ & $0.920 \pm 0.001$ & $*$ & 0.933 \\
\hline $\begin{array}{c}\text { Kinematic viscosity at } 40{ }^{\circ} \mathrm{C} \\
\qquad\left(\mathrm{mm}^{2} \cdot \mathrm{s}^{-1}\right)\end{array}$ & $27.3563 \pm 0.0002$ & $30.61 \pm 0.03$ & $*$ & $*$ \\
\hline
\end{tabular}

* Value was not reported

time, the biodiesel - glycerol mixture was transferred to a separation funnel and left to decant for $24 \mathrm{~h}$. Once the grosser phases were removed, the raw biodiesel went through a washing process using distilled water at $80^{\circ} \mathrm{C}(\mathrm{Ma}$ et al., 2015), and this process was repeated four times. The purified biodiesel was then taken to a stove for drying at $105{ }^{\circ} \mathrm{C}$ for three hours to be dehydrated. Finally, the biodiesel sample had its weight measured to determine the biodiesel weight yield (\%wt) by means of Equation 2, which considers the weight of purified biodiesel $(\mathrm{g})$ and the weight of raw material $(\mathrm{g})$, based on the gravimetric method (Fadhil et al., 2015; Moro et al., 2017; Simonelli et al., 2018).

$\%$ Yield $=\frac{\text { Weight }_{\text {purifiedbiodiesel }}}{\text { Weight }_{\text {rawmaterial }}} * 100$

\subsection{Comparative analysis of means}

Tukey's HSD (honestly significant difference) test was performed. This test is based on the range of distribution and consisted in a multiple comparison analysis between each pair of means (in the presence of PIL) using the molar ratios 4:2, 5:1, and 6:0 (methanol only) with 95\% adjustment. The test determined which means were statically different in the set.

\subsection{Characterization of biodiesel}

The resulting biodiesel was characterized focusing on the conditions that led to the highest weight yield. The goal was to assess whether the quality specifications demanded by Brazilian National Petroleum, Natural Gas, and Biofuels Agency, ANP's resolution 45/2014 (ANP, 2014) were met. The acidity index was determined by titration, in triplicate, using isopropyl alcohol, heptane, and fenoltaleine. The flash point (ASTM D 93-18, 2016) was found using a semiautomatic Petrotest PM4 device. Density at $20{ }^{\circ} \mathrm{C}$ (ASTM D 4052-16, 2016) was measured using an Anton Paar DSA 5000 density meter. Kinematic viscosity at 40 ${ }^{\circ} \mathrm{C}$ (ASTM D 445-17a, 2017) was obtained by Equation 1, which establishes a relationship between absolute viscosity (measured in an Anton Paar MCR 501 rheometer) and density.

\section{RESULTS AND DISCUSSIONS}

\subsection{Characterization of soybean oil}

Table 1 shows the mean values found for the main properties assessed, as well as their standard deviations.

The values of the acidity index and water content were lower than $1 \mathrm{mg} \mathrm{KOH} / \mathrm{g}$ and $0.06 \%$ $(\% \mathrm{~m} / \mathrm{m})$, respectively, confirming the good quality of the raw material, and, therefore, making the oil pre-treatment unnecessary (Wu et al., 2016). The control of properties such as water content and acidity index are fundamental in alkaline homogeneous catalysis.

The water content must be as low as possible so that hydrolysis and saponification reactions are not favored (Issariyakul \& Dalai, 2014; Wu et al., 2016). These reactions reduce the catalyst activity, make separation difficult, and, consequently, lead to lower yields (Encinar et al., 2016). A low acidity value suggests a low amount of free fatty acids (Moro et al., 2017). A high value decreases the rate and yield (Issariyakul \& Dalai, 2014) and influences fuel ageing because acidity increases over time (Alhassan et al., 2014). 


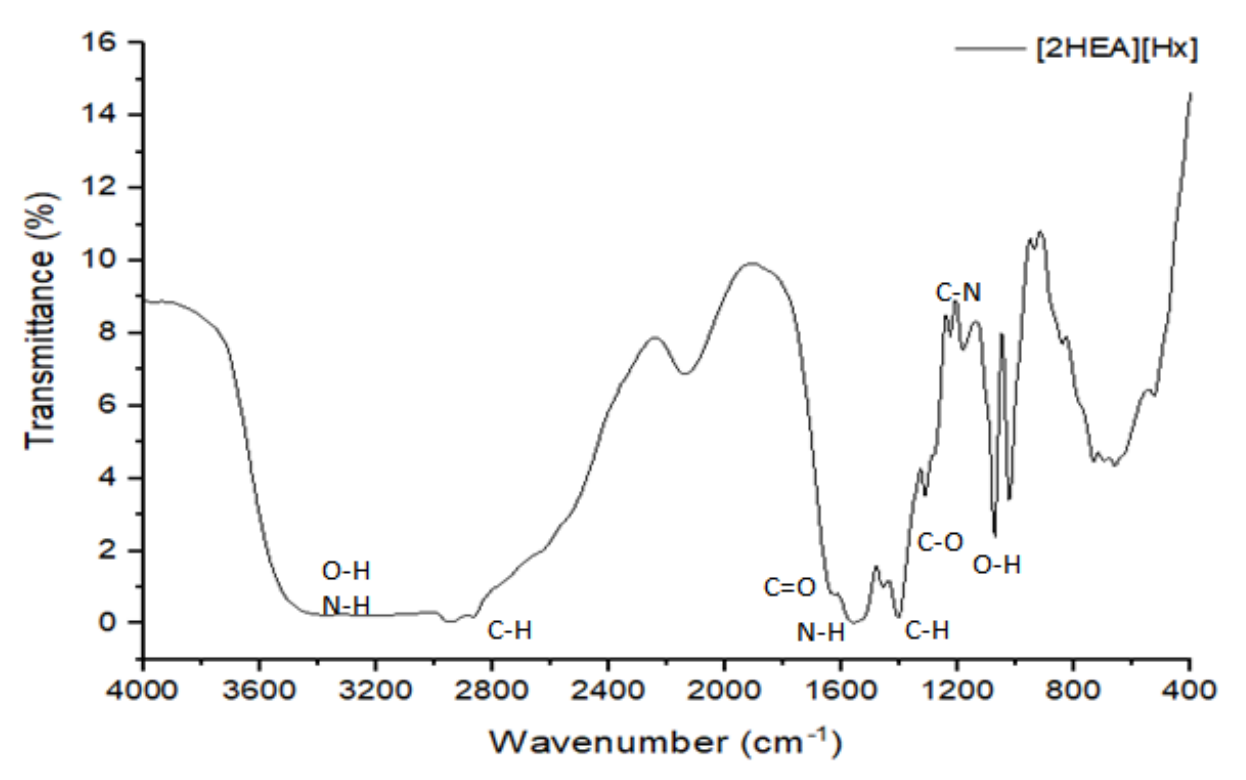

Figure 2. FT-IR spectra for the IL [2HEA][Hx].

\subsection{Characterization of the ionic structure of the PIL [2HEA][Hx]}

FT-IR, NMR and $\% \mathrm{H}_{2} \mathrm{O}$ analyses confirmed the formation of all feature peaks of the structure and gave information about compositions of the PIL [2HEA][Hx]. Figure 2 shows the FT-IR spectra in the region from $400 \mathrm{~cm}^{-1}$ to $4000 \mathrm{~cm}^{-1}$. The formation is confirmed by the presence of feature bands belonging to the bond vibrations $\mathrm{N}-\mathrm{H}$ (deformation), O-H (stretching, deformation), $\mathrm{C}-\mathrm{H}$ $\mathrm{SP}^{3}$ (symmetric and asymmetric stretching of $\mathrm{CH}_{2}$ ), $\mathrm{C}-\mathrm{H}$ (bond $-\mathrm{CH}_{2}$ ), C-N (stretching), $\mathrm{C}=\mathrm{O}$ (stretching of carboxylic acid groups), C-O (hydroxyl group).

Álvarez et al. (2010) and Camargo et al. (2016), in their studies, found two bands that are characteristic of an ammonia structure. One band between $3500-2400 \mathrm{~cm}^{-1}$ produced by the

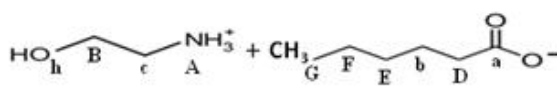
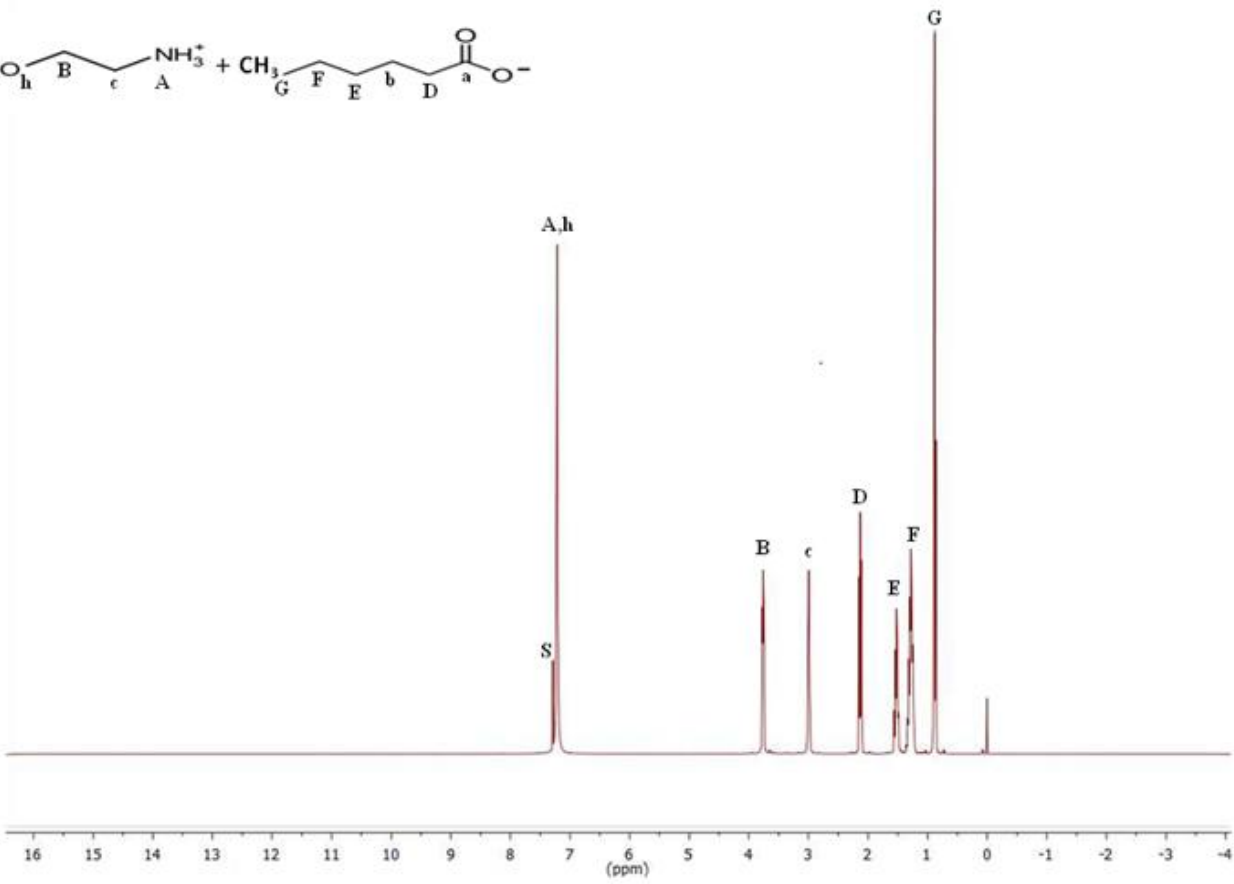

Figure 3. ${ }^{1} \mathrm{HNMR}$ spectra for $[2 \mathrm{HEA}][\mathrm{Hx}] . \mathrm{S}$ : Solvent peak. 


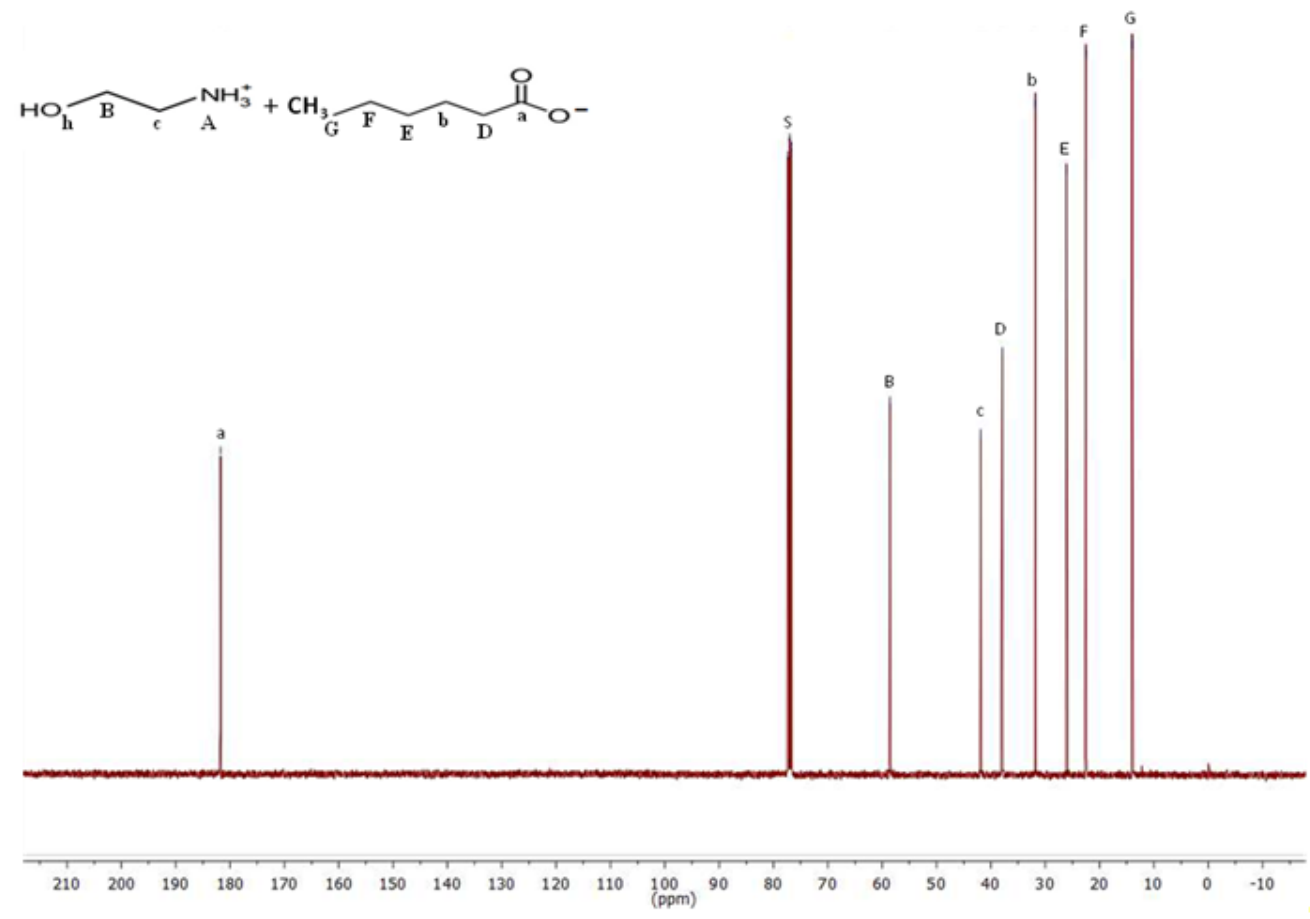

Figure $4 .{ }^{13} \mathrm{CNMR}$ spectra for $[2 \mathrm{HEA}][\mathrm{Hx}]$. S: Solvent peak.

stretching vibration $\mathrm{O}-\mathrm{H}$, and another broader band centered in $1500 \mathrm{~cm}^{-1}$, resulting from the band combination of the carbonyl stretching and the $\mathrm{N}-\mathrm{H}$ plane bending vibrations.

This study verified the formation of structures in the referenced spectra, with one strong stretching vibration band $\mathrm{O}-\mathrm{H}$ at $3300 \mathrm{~cm}^{-1}$, and another band at $1580 \mathrm{~cm}^{-1}$, corresponding to the formation of the $\mathrm{N}-\mathrm{H}$ bond primary amine adsorption band.

The NMR analysis showed the chemical shifts that refer to the structural arrangement and the bonds between carbon and hydrogen atoms contained in the PIL.

Table 2. ${ }^{1} \mathrm{H}$ and ${ }^{13} \mathrm{C}$ chemical shift of [2HEA][Hx].

\begin{tabular}{ccc}
\hline \multirow{2}{*}{ Peaks } & \multicolumn{2}{c}{ Chemical shift (ppm) } \\
\cline { 2 - 3 } & ${ }^{1} \mathrm{H}$ & ${ }^{13} \mathrm{C}$ \\
\hline A,h & 7.22 & - \\
A & - & 181.76 \\
D & 2.13 & 37.91 \\
B & - & 31.83 \\
E & 1.52 & 26.08 \\
F & 1.28 & 22.52 \\
G & 0.88 & 14.00 \\
B & 3.76 & 58.54 \\
C & 2.99 & 41.86 \\
\hline
\end{tabular}

The NMR results proved the correspondence of all hydrogen and carbon peaks in the chemical structure (Figures 3 and 4 and Table 2). Therefore, there was a chemical shift of the anion's proton and a protonation of the cation's hydrogen.

The water content $\left(\% \mathrm{H}_{2} \mathrm{O}\right)$ in the sample was $0.769 \pm 0.071 \%$.

\subsection{Effect of the addition of PIL [2HEA][Hx] to methanol and methanol/ethanol mixture}

Figure 5 shows the mean weight yield (\%) as a function of each molar ratio among alcohols, both in presence and absence of [2HEA][Hx].

A clear increase of the weight yield by adding PIL for molar ratios 6:0 (methanol only) and 5:1, of $3.39 \%$ and $2.20 \%$, respectively, was observed in comparison to the tests without PIL. For the molar ratio 4:2, the PIL did not show any effect on the weight yield. Even though a significant dispersion was observed, the yield was similar, with and without the PIL. This behavior could be explained by the fact that the PIL reached a limit beyond which it could not continue facilitating the mass transfer for this ethanol concentration in the mixture. As a consequence, the weight yield also 


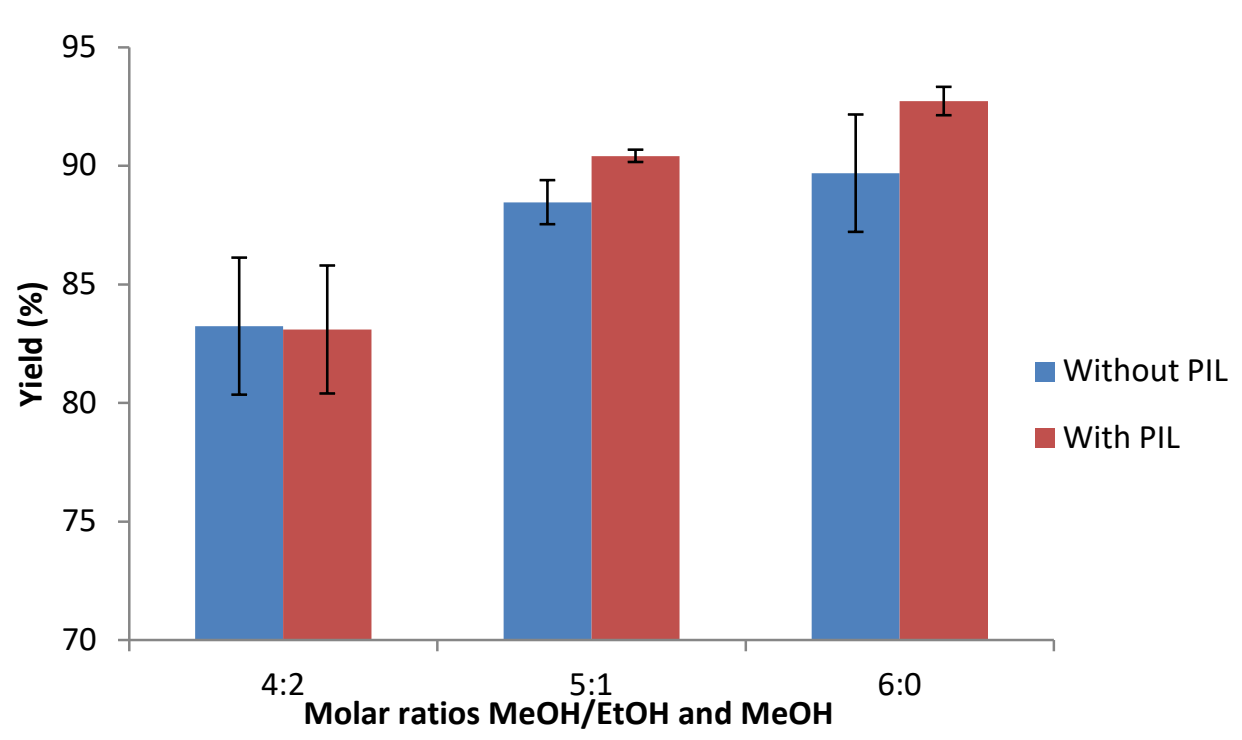

Figure 5. Influence of the addition of [2HEA][Hx] on the biodiesel weight yield.

decreased by $11.59 \%$ with respect to the test with pure methanol (6:0).

Ma et al. (2015) studied the synergistic effect of methanol/ethanol in acid homogeneous catalysis. They reported that the steric hindrance prevailed over the synergy for ethanol proportions greater than $30 \%$, decreasing the process yield. This is similar to the effect observed in this study, although the catalysis was alkaline.

Some studies have reported better reactions and more efficient separations using ILs since they have good solubility with reagents and very low solubility with the final products. Besides, it is also possible that IL provides energy to push out the biodiesel of the phase glycerol and waste at the end of the reaction (Fauzi \& Amin, 2012; Muhammad et al., 2015; Ullah et al., 2018).

The statistical significance of the results obtained in presence of PIL was proved using the confidence intervals in terms of multiples comparisons between pairs of groups and by the difference between mean values by Tukey test. In the $95 \%$ confidence interval, the statistical mean for pairs of groups 5:1 and 4:2, 6:0 and 4:2 were different statically in intervals [3.31-11.34], [5.62 - 13.65] and had a p-value of 0.003 and 0.001, respectively. For comparison of pairs of groups $6: 0$ and 5:1, the Tukey test indicated that mean yields were not statically different within the intervals [-
$1.71-6.33]$, and had a p-value of 0.26 , using a significance level $p<0.05$. Figure 6 shows the comparison of pairs of groups.

When ILs are used as catalysts in the transesterification process, they require a high alcohol-oil ratio, high temperature, and long time. Feng et al. (2017) used a low amount of Brønsted acid AlL, based on quaternary ammonium cation ([CyN1,1PrSO3H][p-TSA], 3.0\% (\%wt/wt) as catalyst to oil, palm oil, and methanol, getting a yield of $98.4 \%$. However, the process variables (24:1 molar ratio, $120^{\circ} \mathrm{C}$, and $150 \mathrm{~min}$ ) had high values. Zanin et al. (2013) used soybean oil and ethanol and achieved conversions above $70 \%$ for $10 \% \mathrm{~mol} / \mathrm{mol}$ with respect to oil of Brønsted acid ionic PIL, based on the imidazole type ( $\mathrm{N}$-methyl-2-pyrrolidonium methyl sulfonate), in worse processes conditions (78 $\left.{ }^{\circ} \mathrm{C}, 8 \mathrm{~h}\right)$.

The results found in this work with the addition of PIL [2HEA][Hx] show that it is possible to produce biodiesel with high weight yields in mild process conditions using low amounts of methanol $(2 \%(\% \mathrm{~m} / \mathrm{m}))$. Similar results were reported by Trindade et al. (2019), yield in mass around $96 \%$ with only $3 \%(\% \mathrm{wt} / \mathrm{wt})$ of PIL [DETA] [Hx], molar ratios alcohol to oil $9: 1$, at $60{ }^{\circ} \mathrm{C}$ and $60 \mathrm{~min}$, and using $\mathrm{KOH}$ catalyst as well. Both results proved the good performance of the LIPs as additive (based on hexanoate anion and cation difference) in transesterification via alkaline catalysis. 


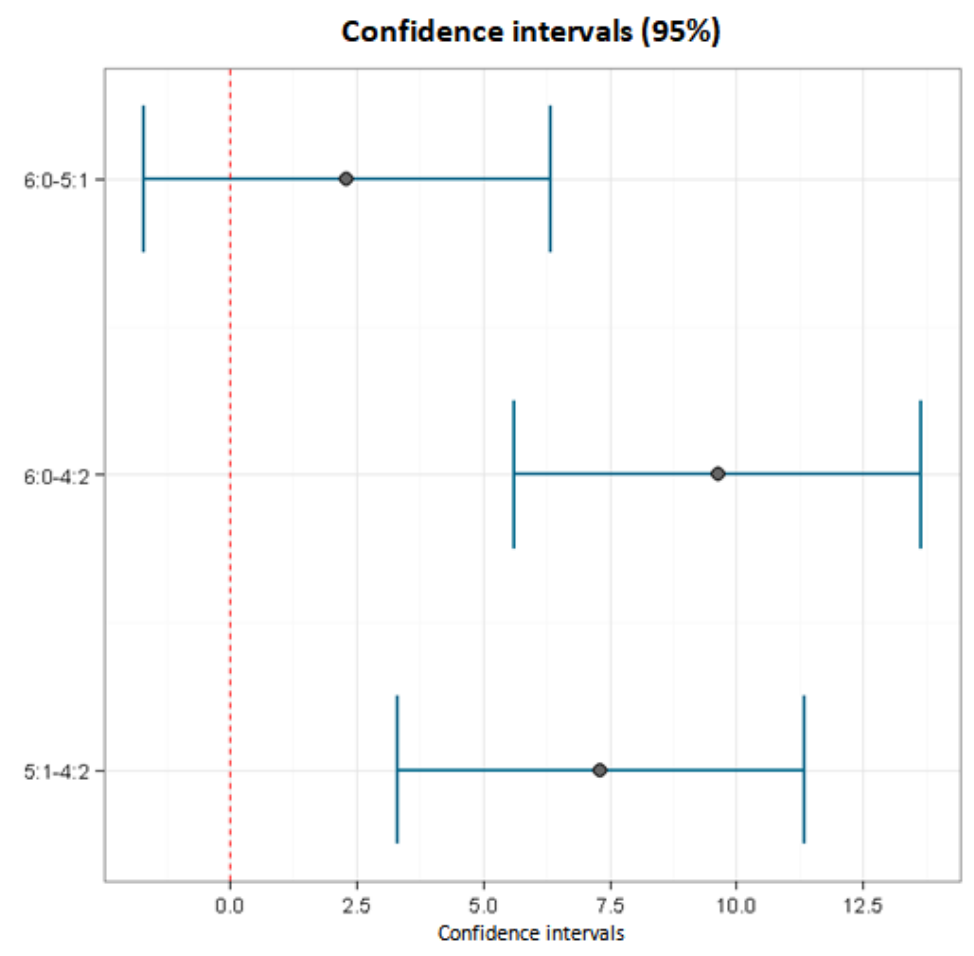

Figure 6. Mean difference of weight yield with $[2 \mathrm{HEA}][\mathrm{Hx}]$ for methanol and methanol/ethanol mixture in the biodiesel production.

Scientific interest in using traditional organic cosolvents and surfactant is due to the fact that they produce high yields in short period of time and at mild temperatures, even room temperature. Basically, they are intended to reduce the interfacial tension in the mixture (Wu et al., 2016; Simonelli et al., 2018).

The effect of the [2HEA][Hx] in the reaction medium can be explained by its good solubility and amphiphilic features. It improves the contact between alcohol/oil phases, thus, allowing the interactions to occur at a molecular level, instead of occurring at the interface. The hydrophobic part of the chain of the PIL [2HEA][Hx] could interact with the alkyl chains of fatty acid molecules forming emulsions (surrounded for the polar molecules) while the polar part formed hydrogen bonds with the methanol or both methanol and ethanol in the interface. The thermodynamic effects of micellization have as consequence the reduction of the interfacial tension, increasing the miscibility between phases and, consequently, the yield.

\subsection{Characterization of biodiesel}

Table 3 shows some quality parameters of biodiesel produced with the addition of the PIL [2HEA][Hx], considering the highest weight yield conditions. Since the mean of 6:0 (methanol only) and methanol/ethanol mixture (molar ratios 5:1) were not significantly different, only the sample (6:0) was characterized. The results show that the properties meet the ANP's specifications, thus, attesting the quality of the product.

Table 3. Biodiesel Properties using $[2 \mathrm{HEA}][\mathrm{Hx}]$.

\begin{tabular}{ccc}
\hline Properties & Value & ANP 45/2014 \\
\hline Kinematic viscosity at $40{ }^{\circ} \mathrm{Cmm}^{2} \cdot \mathrm{s}^{-1}$ & 4.3239 & $3.0-6.0$ \\
Density at $20^{\circ} \mathrm{C}\left(\mathrm{kg} / \mathrm{m}^{3}\right)$ & $882.690000 \pm 0.000001$ & $850-900$ \\
Acidity index $(\mathrm{mgKOH} / \mathrm{g})$ & $0.18 \pm 0.06$ & $<0.5 \mathrm{mgKOH} / \mathrm{g}$ \\
Flash point $\left({ }^{\circ} \mathrm{C}\right)$ & 186 & minimum 100 \\
\hline
\end{tabular}




\section{CONCLUSIONS}

Because of the known mass transfer restrictions in transesterification reaction, generally, it is necessary to increase the process variables to improve reaction rate, and yield. This research sought to improve the miscibility between oil and alcohol, without relying on increasing the quantities of the process variables. The addition of PIL $[2 \mathrm{HEA}][\mathrm{Hx}]$, which has a surfactant effect, in a low quantity, enhanced the miscibility in the reaction, in a manner similar to organic cosolvents, but under much milder conditions. PIL is also much less harmful both to operators and to the environment than organic co-solvents.

The PIL [2HEA][Hx] showed good performance in the reaction medium when added in small amounts and under mild process conditions (temperature and time). It favored the surfactant effect, improving the interaction between alcohol and oil phases, separation (biodiesel - glycerol), and weight yield.

The highest weight yield achieved by adding PIL to [2HEA] $[\mathrm{Hx}]$ at $2 \%(\% \mathrm{~m} / \mathrm{m})$ was $92.72 \%$. This value was achieved with both the use of pure methanol and with the methanol/ethanol mixture (molar ratios 5:1), considering that mean values were not statistically different. The process conditions were $6: 1$ alcohol / oil molar ratio, $1.5 \%$ (\%wt/wt) KOH, $60^{\circ} \mathrm{C}$, and $30 \mathrm{~min}$.

When the amount of methanol decreases in the reaction and the ethanol increases in the lowest molar ratio assessed (4:2), the weight yields were similar both in presence and absence of PIL, therefore, not justifying an increase in the amount of ethanol for higher molar ratios.

\section{ACKNOWLEDGMENTS}

This study was financed in part by Coordenação de Aperfeiçoamento de Pessoal de Nível Superior Brazil (CAPES) - Finance Code 001. S. Mattedi acknowledges CNPq (Grant 306640/2016) and FAPESB/SECTI (Project APP0075/2016).

\section{REFERENCES}

ABNT NBR 11115. Insumos - Substâncias Graxas - Determinação do Índice de Acidez. Associação Brasileira de Normas Técnicas, 2014. (in Portuguese).

Alhassan, Y.; Kumar, N.; Bugaje, I. M.; Pali, H. S.; Kathkar, P. Co-solvents transesterification of cotton seed oil into biodiesel: Effects of reaction conditions on quality of fatty acids methyl esters. Energy Conversion and Management, v. 84, p. 640-648, 2014.

https://doi.org/10.1016/j.enconman.2014.04.080

ANP - Agência Nacional de Petróleo, Gás Natural e Biocombustíveis. Resolução ANP № 45, de 25.8.2014 - DOU 26.8.2014 - Especificações do biodiesel, 2014. (in Portuguese)

Álvarez, V.; Dosil, N.; Cabaleiro, R. G.; Mattedi, S.; Pastor, M. M.; Iglesias, M.; Navaza, J. M. Brønsted ionic liquids for sustainable processes: Synthesis and physical properties. Journal of Chemical Engineering, v. 55, p. 625-632, 2010. https://doi.org/10.1021/je900550v

ANVISA - Agência Nacional de Vigilância Sanitária. Guia de controle de qualidade de produtos cosméticos2a edição, 2008. (in Portuguese).

ASTM D4052-16. Standard Test Method for Density, Relative Density, and API Gravity of Liquids by Digital Density Meter. ASTM International, West Conshohocken, PA, 2016.

ASTM D 445-17a. Standard Test Method for Kinematic Viscosity of Transparent and Opaque Liquids (and Dynamic Viscosity). ASTM International, West Conshohocken, PA, 2017.

ASTM D 93-18: Standard Test Methods for Flash Point by Pensky-Martens Closed Cup Tester. ASTM International, West Conshohocken, PA, 2016.

Camargo, D.; Andrade, R. S.; Ferreira, G. A., Mazzer, H., Filho L. C.; Iglesias, M. Investigation of the rheological properties of protic ionic liquids. Journal of Physical Organic Chemistry, v. 29, p. 604-612, 2016. https://doi.org/10.1002/poc.3553 
Cintra, J. S. A.; Pedroza, G. A. G.; Portela, M. N.; Silvany, T. C de C.; Santos, L. C. L.; Lobato, A. K. C. L. Influência do tempo de reação na produção de biodiesel via catálise heterogênea. Holos, v. 01, p. 195-204, 2017.

https://doi.org/10.15628/holos.2017.5197

Encinar, J.; Pardal, A.; Sanchez, N. An improvement to the transesterification process by the use of co-solvents to produce biodiesel. Fuel, v 166, p. 51-58, 2016.

https://doi.org/10.1016/i.fuel.2015.10.110

Fadhil, A. B.; Al-Tikrity, E. T. B.; Albadree, M. A. Transesterification of a novel feedstock, Cyprinuscarpio fish oil: Influence of co-solvent and characterization of biodiesel. Fuel, v. 162, p. 215223, 2015. https://doi.org/10.1016/i.fuel.2015.09.001

Fan, Y.; Wang, X.; Zhang, L; Li, J.; Yang, L.; Gao, P.; Zhou, Z. Lipase-catalyzed synthesis of biodiesel in a hydroxyl-functionalized ionic liquid. Chemical Engineering Research and Design, v. 132, p. 199207, 2018.

https://doi.org/10.1016/i.cherd.2018.01.020

Fauzi, A. H. M.; Amin, N. A. S. An overview of ionic liquids as solvents in biodiesel synthesis. Renewable and Sustainable Energy Reviews, v. 16, p. 5770-5786, 2012.

https://doi.org/10.1016/i.rser.2012.06.022

Feng, Y.; Qiu, T.; Yang, J.; Li, L.; Wang, X.; Wang $H$. Transesterification of palm oil to biodiesel using Brønsted acidic ionic liquid as high-efficient and eco-friendly catalyst. Chinese Journal of Chemical Engineering, v. 25, p. 1222-1229, 2017.

https://doi.org/10.1016/i.cjche.2017.06.027

Guimarães, A. K. V.; Jesus, A. A.; Oliveira, H. N. M.; Barros Neto, E. L.; Gondim, A. D.; ChiavoneFilho, O. Biodiesel from oiticica oil (Licaniarígida, Benth): production, thermogravimetric, and oxidative stability studies. Brazilian Journal of Petroleum and Gas, v. 12, n.2, p. 107-122, 2018. https://doi.org/10.5419/bjpg2018-0011

Issariyakul, T.; Dalai, A. K. Biodiesel from vegetables oil. Renewable and Sustainable Energy Reviews, v. 31, p. 446-471, 2014. https://doi.org/10.1016/i.rser.2013.11.001

Keera, S. T.; El Sabagh, S. M.; Taman, A. R. Transesterification of vegetable oil to biodiesel fuel using alkaline catalyst. Fuel, v. 90, p. 42-47, 2011. https://doi.org/10.1016/i.fuel.2010.07.046
Khudhair, M. M.; Husain, S. S.; Jassim, Z. M.; Salih, S. M. Transesterification of castor oil by using methanol and ethanol (50/50) Mixture. Engineering and Technology Journal, v. 36, p. 5963, 2018. https://doi.org/10.30684/etj.36.1B.10

Lam, M. K.; Lee, K. T. Mixed methanol-ethanol technology to produce greener biodiesel from waste cooking oil: A breakthrough for $\mathrm{SO}_{4} 2$ /SnO2-SiO2 catalyst. Fuel Processing Technology, v. 92, p. 1639-1945, 2011.

https://doi.org/10.1016/i.fuproc.2011.04.012

Li, Q; Xu, J.; Du, W.; Li, Y.; Liu, D. Ethanol as the acyl acceptor for biodiesel production. Renewable and Sustainable Energy Reviews, v. 25, p. 742-748, 2013. https://doi.org/10.1016/j.rser.2013.05.043

Ma, Y.; Wang, Q.; Zheng, L.; Gao, Z.; Wang, Q.; $\mathrm{Ma}, \quad Y$. Mixed methanol/ethanol on transesterification of waste cooking oil using $\mathrm{Mg} / \mathrm{Al}$ hydrotalcite catalyst. Energy, v. 107, p. 523-531, 2016. https://doi.org/10.1016/j.energy.2016.04.066

Ma, Y.; Zheng, L.; Wang, Q.; Ma, H.; Niu, R.; Gao, Z. Synergistic effect of mixed methanol/ethanol on transesterification of waste food oil using pToluenesulfonic acid as catalyst. Environmental Progress \& Sustainable Energy, v. 34, n 5, p. 15471553, 2015. https://doi.org/10.1002/ep.12140

Moro, M.K.; Andreatta, D.; Oliveira, B.C.; Bimbato, R. M.; Simonelli, G. Aplication of central composite rotational delineation (CCRD) in the study of biodiesel properties. Brazilian Journal of Petroleum and Gas, v. 11, n.4, p. 187-195, 2017. https://doi.org/10.5419/bjpg2017-0016

Muhammad, N.; Elsheikh, Y. A.; Mutalib, M. I. A.; Bazmi, A. A.; Khan, R. A.; Khan, H.; Rafiq, S.; Man, Z.; Khan, I. An overview of the role of ionic liquids in biodiesel reactions. Journal of Industrial and Engineering Chemistry, v. 21, p. 1-10, 2015. https://doi.org/10.1016/i.jiec.2014.01.046

Penttila, A.; Uusi-Kyyni, P.; Alopaeus, V. Distillable Protic Ionic Liquid 2-(Hydroxy) ethylammonium Acetate (2- HEAA): Density, Vapor Pressure, Vapor-Liquid Equilibrium, and SolidLiquid Equilibrium. Industrial \& Engineering Chemistry Researches, v. 53, p. 19322-19330, 2014. https://doi.org/10.1021/ie503823a 
Pinto, R. R.; Mattedi, S.; Aznar, M. Synthesis and physical properties of three ionic liquids with ethylammonium cation. Chemical Engineering Transactions, v. 43, p. 1165-1170, 2015. https://doi.org/10.3303/CET1543195

Santos, D., Costa, F., Franceschi, E., Santos, A., Dariva, C., Mattedi, S. Synthesis and physicochemical properties of two protic ionic liquids based on stearate anion. Fluid Phase Equilibria, v. 376, p. 132-140, 2014.

https://doi.org/10.1016/i.fluid.2014.05.043

Simonelli, G; Moraes, C.; Pires, C. A. D. M.; Santos, L.C L. Multivariate study and optimization of biodiesel production using commercial surfactants. Chemical Industry and Chemical Engineering Quarterly, v. 00, p. 31-31, 2018.

Trindade, M. E. J.; Mattedi, S.; Simonelli, G.; Santos, L. C. L. Use of protic ionic liquid ([DETA][Hx]) as co-solvent for biodiesel production. Brazilian Journal of Petroleum and Gas, 2019 (Accepted). https://doi.org/10.5419/bjpg2019-0006

Troter, D. Z.; Todorović, Z. B.; Đokić-Stojanović, D. R.; Stamenković, O. S., Veljković, V. B. Application of ionic liquids and deep eutectic solvents in biodiesel production: A review. Renewable and Sustainable Energy Reviews, v. 61, p. 473-500, 2016.

https://doi.org/10.1016/j.rser.2016.04.011
Ullah, Z.; Kang, A. S.; Muhammad, N.; Ullah, R.; Alqahtani, A. S.; Shah, S. N.; Ghanem, O. B.; Bustam, M. A; Man, Z.A review on ionic liquids as perspective catalysts in transesterification of different feedstock oil into biodiesel. Journal of Molecular Liquids, v.266, p. 673-686, 2018. https://doi.org/10.1016/i.molliq.2018.06.024

Verma, P.; Sharma, M. P. Comparative analysis of effect of methanol and ethanol on Karanja biodiesel production and its optimization. Fuel, v. 180, p. 164-174, 2016. https://doi.org/10.1016/j.fuel.2016.04.035

Wu, L.; Huang, K.; Wei, T.; Lin, Z.; Zou, Y.; Tong, Z. Process intensification of $\mathrm{NaOH}$-catalyzed transesterification for biodiesel production by the use of bentonite and co-solvent(diethyl ether). Fuel, v. 186, p. 597-604, 2016.

https://doi.org/10.1016/j.fuel.2016.08.106

Zanin, F. G.; Macedo, A.; Archilha, M. V. L R.; Wendler, E. P.; Dos Santos, A. A. A one-pot glycerol-based additive-blended ethyl biodiesel production: A green process. Bioresource Technology, v. 143, p. 126 - 130, 2013. https://doi.org/10.1016/i.biortech.2013.05.106 